\title{
Treatment of a tuberculous empyema with simultaneous oral and intrapleural antituberculosis drugs
}

\author{
Richard Long MD FCCP1 , James Barrie MD², Kenneth Stewart MD ${ }^{3}$, Charles A Peloquin PharmD ${ }^{4}$
}

\begin{abstract}
R Long, J Barrie, K Stewart, CA Peloquin. Treatment of a tuberculous empyema with simultaneous oral and intrapleural antituberculosis drugs. Can Respir J 2008;15(5):241-243.

A 71-year-old man was diagnosed with an uncomplicated tuberculous (TB) empyema. Differential penetration of anti-TB drugs, believed to explain the phenomenon of acquired drug resistance in TB empyema, was confirmed by measurement of serum and pleural fluid anti-TB drug concentrations. Simultaneous oral and intrapleural anti-TB drugs were administered and a cure was achieved. The present case is discussed in the context of the literature on acquired drug resistance in TB empyema. It is argued that high-end doses of oral drugs or combined oral plus intrapleural drugs, along with tube thoracostomy or intermittent thoracentesis, will cure uncomplicated TB empyema without threatening to induce drug resistance or having to resort to surgery.
\end{abstract}

Key Words: Acquired drug resistance; Tuberculous empyema

$\mathrm{T}$ uberculous (TB) empyema is a chronic, active infection of the pleural space and a rare complication of pleuropulmonary TB (1). Its management may vary depending on the coexistence of spontaneous drainage phenomena (bronchopleural fistula [BPF] or empyema necessitatis) as well as the general and lung health of the patient. As a rule, anti-TB drug treatment alone cannot be relied on for cure. Virtually all cases require some form of external drainage. However, even when spontaneous drainage has occurred via a BPF, anti-TB drug treatment alone has been problematic - orally administered anti-TB drugs have resulted in acquired drug resistance, presumably because of differential penetration of drugs through the thick fibrocalcific wall of the empyema (1-4).

In the past, drainage has been provided using a wide variety of surgical procedures, including decortication to allow re-expansion of the trapped lung and decortication plus pneumonectomy to remove a lung that is predicted to cause ongoing morbidity. However, experience in the performance of these procedures may be lacking. As well, patients may be older or have comorbidities. Nonsurgical drainage may be adequate if it is possible to provide therapeutic drug exposure.

\section{CASE PRESENTATION}

In 1954, a 20-year-old man was diagnosed with right-sided TB pleurisy. He was given 12 months of streptomycin and paraaminosalicylic acid in a sanatorium. In the spring of 2005,

\section{Le traitement d'un empyème tuberculeux par l'administration simultanée d'antituberculeux par voie orale et intrapleurale}

\begin{abstract}
Un homme de 71 ans a reçu un diagnostic d'empyème tuberculeux (TB) sans complication. La pénétration différentielle des médicaments anti$\mathrm{TB}$, qu'on présumait explicative du phénomène d'acquisition de la résistance aux médicaments en cas d'empyème $T B$, a été confirmée par la mesure des concentrations d'anti-TB dans le sérum et le liquide pleural On a administré simultanément des anti-TB par voie orale et intrapleurale et on a pu guérir le patient. Le présent cas est présenté d'après les publications sur la résistance acquise aux médicaments en cas d'empyème TB. On avance que des doses élevées de médicaments par voie orale ou que l'association de médicaments par voie orale et intrapleurale, conjointement avec une thoracostomie par drain ou à une thoracentèse intermittente, guérira un empyème TB sans complication, sans menacer de provoquer une résistance aux médicaments ou sans qu'il soit nécessaire d'opérer.
\end{abstract}

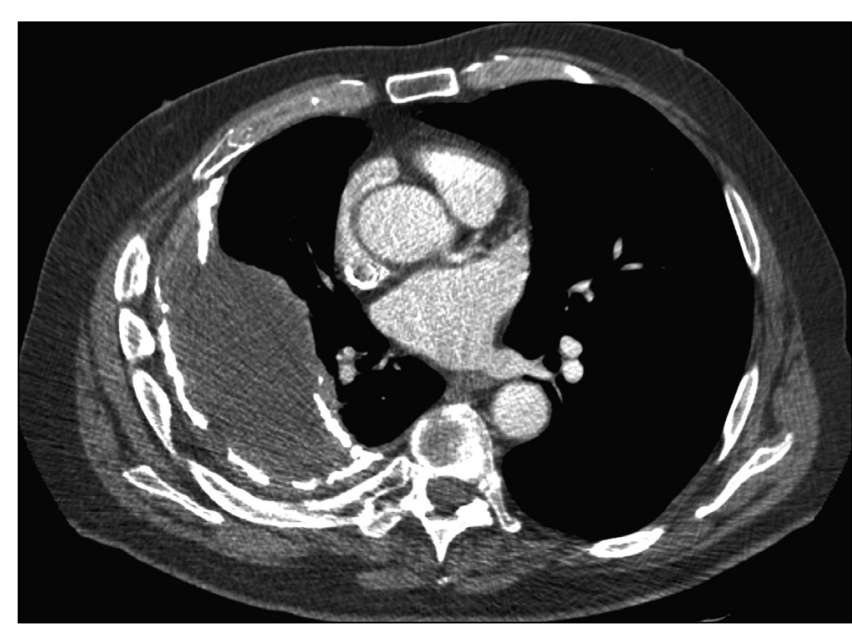

Figure 1) A computed tomography image reveals right-sided volume loss and a pleural rind with a focal fluid collection. Note the calcification of both parietal and visceral pleura, as well as the enlargement of the adjacent ribs on the right side

during the investigation of a swallowing difficulty and weight loss that ultimately was proven to be due to squamous cell carcinoma of the hypopharynx, he was diagnosed with a rightsided TB empyema (Figure 1). Pleural fluid was opaque and

${ }^{1}$ Department of Medicine; ${ }^{2}$ Department of Radiology; ${ }^{3}$ Department of Surgery, University of Alberta, Edmonton, Alberta; ${ }^{4}$ Infectious Disease Pharmacokinetics Laboratory, National Jewish Medical and Research Center, Denver, Colorado, USA

Correspondence and reprints: Dr Richard Long, Tuberculosis Program Evaluation and Research Unit, Room 8325, Aberhart Centre 1,

11402 University Avenue, Edmonton, Alberta T6G 2J3. Telephone 780-407-1427, fax 780-407-1429, e-mail richard.long@ualberta.ca 
TABLE 1

Antituberculosis drug concentrations in serum and pleural fluid

\begin{tabular}{|c|c|c|c|c|c|c|c|}
\hline \multirow[b]{3}{*}{ Drug, dose } & \multirow{3}{*}{$\begin{array}{l}\text { Usual } C_{\max } \\
\mu g / \mathrm{mL}^{*}\end{array}$} & \multirow{3}{*}{$\begin{array}{l}\text { Usual MIC, } \\
\mu \mathrm{g} / \mathrm{mL}\end{array}$} & \multirow{3}{*}{$\begin{array}{c}\text { Usual } \\
\mathrm{C}_{\max } / \mathrm{MIC}\end{array}$} & \multirow{3}{*}{$\begin{array}{l}\text { Time of sample drawn } \\
\text { postdose, } \mathbf{h}\end{array}$} & \multicolumn{3}{|c|}{ Sample concentration, $\mu \mathrm{g} / \mathrm{mL}$} \\
\hline & & & & & \multirow{2}{*}{$\begin{array}{l}\text { Serum } \\
\text { Day } 8^{\dagger}\end{array}$} & \multicolumn{2}{|c|}{ Pleural fluid } \\
\hline & & & & & & Day $8^{\dagger}$ & Day $9^{\dagger}$ \\
\hline \multirow[t]{3}{*}{$300 \mathrm{mg}$} & & & & 1 & 3.25 & 0.70 & 0.66 \\
\hline & & & & 2 & 2.38 & 0.74 & 0.64 \\
\hline & & & & 6 & 1.12 & 0.96 & \\
\hline \multirow[t]{3}{*}{$600 \mathrm{mg}$} & & & & 1 & 1.23 & 0.41 & 0.00 \\
\hline & & & & 2 & 8.01 & 0.42 & 0.40 \\
\hline & & & & 6 & 3.91 & 0.48 & \\
\hline Pyrazinamide, & $20-50$ & & & 0 (baseline) & 12.81 & 18.55 & \\
\hline $2000 \mathrm{mg}$ & & & & 1 & 45.82 & 19.50 & 18.03 \\
\hline
\end{tabular}

${ }^{*}$ Data are from reference $10 ;{ }^{\dagger}$ Days 8 and 9 of treatment with oral isoniazid and rifampin; days 4 and 5 of treatment with oral pyrazinamide. $C_{\text {max }}$ Maximum concentration; MIC Minimum inhibitory concentration

saffron coloured. It had a total protein concentration of $54 \mathrm{~g} / \mathrm{L}$ (simultaneous plasma protein $68 \mathrm{~g} / \mathrm{L}$ ), a glucose concentration of $0.9 \mathrm{mmol} / \mathrm{L}$ (simultaneous plasma glucose $5.1 \mathrm{mmol} / \mathrm{L}$ ) and a lactate dehydrogenase level of $1155 \mathrm{U} / \mathrm{L}$. A pleural fluid acid-fast bacilli smear was positive; a pleural fluid culture was positive for Mycobacterium tuberculosis susceptible to all first-line anti-TB drugs. The fact that DNA fingerprintmatched isolates were not present in the province of Alberta during the 15 years immediately preceding the date of diagnosis supported the clinical supposition that his current episode of disease represented a late relapse of TB pleurisy. A pleural fluid Gram stain, routine aerobic and anaerobic culture, direct examination for fungi and fungal culture were all negative. He was HIV seronegative.

On the August 18, 2005, he was started on oral anti-TB drugs: isoniazid (INH) $300 \mathrm{mg}$, rifampin $600 \mathrm{mg}$, pyrazinamide $2000 \mathrm{mg}$ (22 mg/kg total body weight) and ethambutol $2400 \mathrm{mg}$ ( $26 \mathrm{mg} / \mathrm{kg}$ total body weight). His body weight was $92.2 \mathrm{~kg}$ and he had a body mass index of $26.9 \mathrm{~kg} / \mathrm{m}^{2}$. Treatment was daily in the initial phase and twice weekly (INH $900 \mathrm{mg}$ and rifampin $600 \mathrm{mg}$ for seven months) in the continuation phase. All treatment was directly observed.

To assess the adequacy of TB drug exposure, a 10 Fr Navarre catheter was inserted into the empyema space under computed tomography guidance. Baseline and postdose peripheral blood and pleural fluid samples were drawn, and anti-TB drug concentrations were measured using high performance liquid chromatography (for INH and rifampin) or gas chromatography with mass spectrometry (for pyrazinamide) at the National Jewish Medical and Research Center, USA. Serum concentrations rose to the average maximum concentration $\left(\mathrm{C}_{\max }\right)$ at $1 \mathrm{~h}$ to $2 \mathrm{~h}$ postdose, while pleural fluid $\mathrm{C}_{\max }$ was low for all drugs and time to $\mathrm{C}_{\max }\left(\mathrm{T}_{\max }\right)$ was increased (Table 1). Pleural fluid $\mathrm{C}_{\max }$ was $30 \%, 6 \%$ and $49 \%$ of serum $\mathrm{C}_{\max }$, for INH, rifampin and pyrazinamide, respectively. Repeat postdose concentrations were confirmatory.

To provide external drainage, a $28 \mathrm{Fr}$ chest tube was inserted into the empyema space, estimated by computed tomography to be approximately $150 \mathrm{~mL}$ in volume. To ensure therapeutic drug exposure, a protocol of intrapleural (empyema space) treatments was commenced. It consisted of twice-weekly treatments for six months starting October 5, 2005. On each treatment day, $150 \mathrm{~mL}$ of fresh drug-containing solution was prepared. Drugs were chosen on the basis of availability in parenteral formulation, drug susceptibility test results, ability to prevent nonmycobacterial superinfection and cost; INH $(20 \mu \mathrm{g} / \mathrm{mL}$ or $3 \mathrm{mg})$, amikacin $(80 \mu \mathrm{g} / \mathrm{mL}$ or $12 \mathrm{mg})$ and levofloxacin $(10 \mu \mathrm{g} / \mathrm{mL}$ or $1.5 \mathrm{mg})$. Drug concentrations were purposely high-end relative to usual serum concentrations, and a degree of dilution was assumed. The empyema space was first irrigated with $150 \mathrm{~mL}$ of nondrug-containing sterile saline (in the Navarre catheter and out the chest tube). The drug-containing solution was then infused; dwell time was two to three days. The duration of intrapleural treatment took into account the time to cure uncomplicated pulmonary TB, but was otherwise empirical. Nonmycobacterial superinfection of the pleural space did not occur despite cancer chemotherapy-induced leukopenia.

Permanent drainage was provided, local tumour was excluded and treatment outcome was confirmed at surgery on May 17, 2006 (5). All tissue and fluid samples were negative for AFB on smear and culture. No local tumour was identified. Unfortunately, the patient died four months later of complications of his hypopharyngeal tumour.

\section{DISCUSSION}

We describe a patient with classical TB empyema managed in a manner unique to $\mathrm{TB}$ empyema but known to chronic abscess. The treatment was designed to provide a timely cure without inducing drug resistance and without resorting to major surgery. It recognized the relatively low morbidity of the lesion despite its remarkable chronicity.

Pharmacokinetic studies confirmed the differential penetration of standard anti-TB drugs into the empyema space and the existence of conditions favourable to the acquisition of resistance. Pleural fluid $\mathrm{T}_{\max }$ was increased and pleural fluid $\mathrm{C}_{\max }$ was $30 \%, 6 \%$ and $49 \%$ of serum $C_{\max }$ for INH, rifampin and pyrazinamide, respectively. In the only other case in which pleural fluid drug concentrations have been compared with serum concentrations, Elliott et al (3) found pleural fluid $\mathrm{T}_{\text {max }}$ 
to be increased and pleural fluid $\mathrm{C}_{\max }$ to be $4 \%, 34 \%$ and $48 \%$ of serum $\mathrm{C}_{\max }$ for rifampin, streptomycin and ofloxacin, respectively. In that case, pleural fluid as well as serum $\mathrm{T}_{\max }$ and $\mathrm{C}_{\max }$ for ethambutol were virtually identical.

Acquired drug resistance has been reported in eight cases of TB empyema (1-4). All cases were resistant to INH, presumably because it was the only drug that achieved therapeutic concentrations in the pleural space. Using the $\mathrm{C}_{\max } /$ minimum inhibitory concentration (MIC) ratio - an approximate measure of the potency of INH and rifampin in the pleural space, with a value of greater than four indicating probable effectiveness (6) - INH was effective at $19.2(0.96 / 0.05)$ and rifampin was ineffective at $2.4(0.48 / 0.20)$. The relationship between $\mathrm{C}_{\max }$ and MIC is less clear for pyrazinamide. MICs of pyrazinamide for susceptible strains of $M$ tuberculosis, which were detemined using radiometric techniques, ranged between $6.2 \mu \mathrm{g} / \mathrm{mL}$ or less and $50 \mu \mathrm{g} / \mathrm{mL}$ when tested at a $\mathrm{pH}$ of $5.5(7)$. The recommended break point for susceptibility testing is less than $100 \mu \mathrm{g} / \mathrm{mL}$, while the therapeutic range in vivo is $20 \mu \mathrm{g} / \mathrm{mL}$ to $50 \mu \mathrm{g} / \mathrm{mL}$. It is probable that the achievable pleural fluid concentrations of pyrazinamide in our patient were therapeutic, especially given that pyrazinamide is only effective in an acidic environment and acidity is a classic feature of TB empyema. However, as a companion drug in the treatment of pulmonary $\mathrm{TB}$, pyrazinamide cannot be relied on to protect against INH resistance (8).

All cases of acquired drug resistance in TB empyema also had a BPF, a complication we speculate contributed to the acquisition of resistance by improving oxygenation, mycobacterial growth and the number of resistant mutants. In the

\section{REFERENCES}

1. Sahn SA, Iseman MD. Tuberculous empyema. Semin Respir Infect 1999;14:82-7.

2. Reeve PA, Seaton D. Tuberculous empyema - a case history extending over 30 years. Tubercle 1986;67:147-50.

3. Elliott AM, Berning SE, Iseman MD, Peloquin CA. Failure of drug penetration and acquisition of drug resistance in chronic tuberculous empyema. Tuber Lung Dis 1995;76:463-7.

4. Iseman MD, Madsen LA. Chronic tuberculous empyema with bronchopleural fistula resulting in treatment failure and progressive drug resistance. Chest 1991;100:124-7.

5. Minami M, Kawauchi N, Yoshikawa K, et al. Malignancy associated with chronic empyema: Radiologic assessment. Radiology 1991;178;417-23. absence of a BPF, Neihart et al (9) cured a patient with TB empyema using a 24-month course of INH and ethambutol (rifampin was also administered but is unlikely to have achieved therapeutic concentrations in the empyema) in combination with intermittent thoracentesis.

Taken together, our own experience and that of Neihart et al (9) and Elliott et al (3) suggest the following:

- it is possible to cure TB empyema, at least one that is uncomplicated by BPF, without resorting to surgical drainage;

- 12 to 18 months of high-end doses of oral INH, pyrazinamide and ethambutol, together with tube thoracostomy or intermittent thoracentesis, are curative without threatening to induce drug resistance; and

- combined oral plus intrapleural anti-TB drugs, along with tube thoracostomy, while offering theoretical advantages (reduced time to cure, reduced likelihood of drug resistance), may not be required in all cases.

ACKNOWLEDGEMENTS: The authors are very grateful to Carolyn Comin and the staff of the TB inpatient unit at the University of Alberta Hospital, Pieter De Wet and the staff of the Associate Medical Centre (McLennan, Alberta), and Dennis Kunimoto, Greg Tyrrell and the staff of the Provincial Laboratory for Public Health (Alberta) for their assistance in the management of the patient. No outside financial support was sought or received for this case study. There are no conflicts of interest for any of the above authors.

6. Heifets LB. Antituberculous drugs: Antimicrobial activity in vitro. In: Heifets LB, ed. Drug susceptibility in the chemotherapy of mycobacterial infections. Florida: CRC Press 1991:13-57.

7. Salfinger M, Heifets LB. Determination of pyrazinamide MICs for Mycobacterium tuberculosis at different $\mathrm{pHs}$ by the radiometric method. Antimicrob Agents Chemother 1988;32:1002-4.

8. Mitchison DA. The action of antituberculosis drugs in short-course chemotherapy. Tubercle 1985;66:219-25.

9. Neihart RE, Hof DG. Successful nonsurgical treatment of tuberculous empyema in an irreducible pleural space. Chest 1985;88:792-4.

10. Peloquin CA. Therapeutic drug monitoring in the treatment of tuberculosis. Drugs 2002;62:2169-83. 


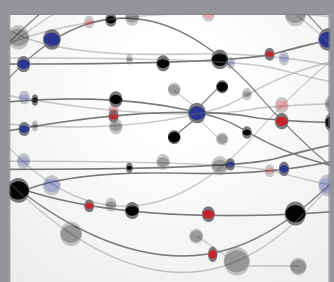

The Scientific World Journal
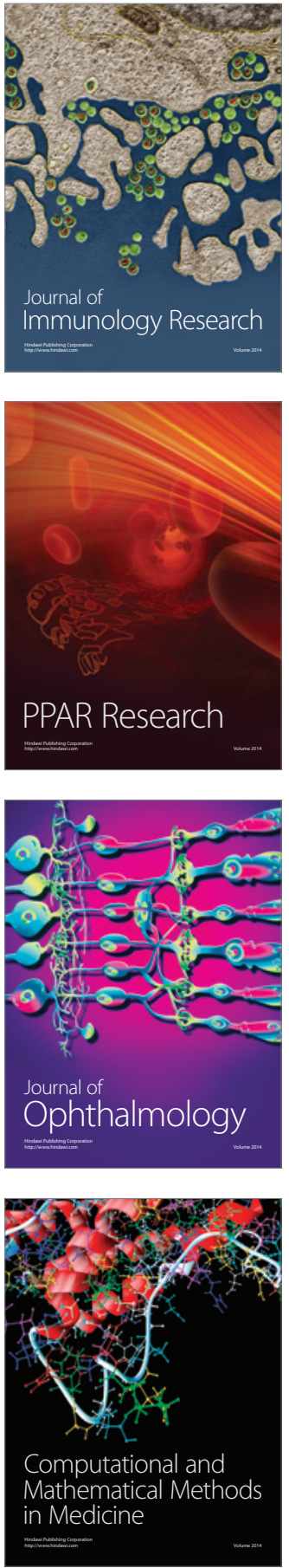

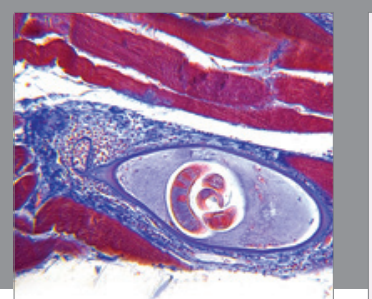

Gastroenterology Research and Practice

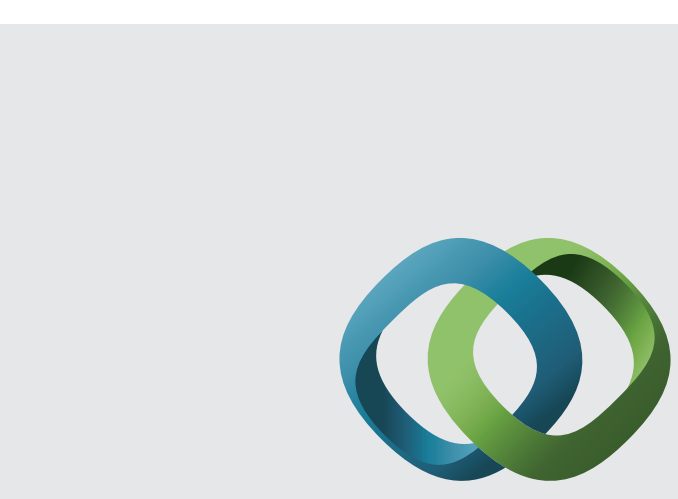

\section{Hindawi}

Submit your manuscripts at

http://www.hindawi.com
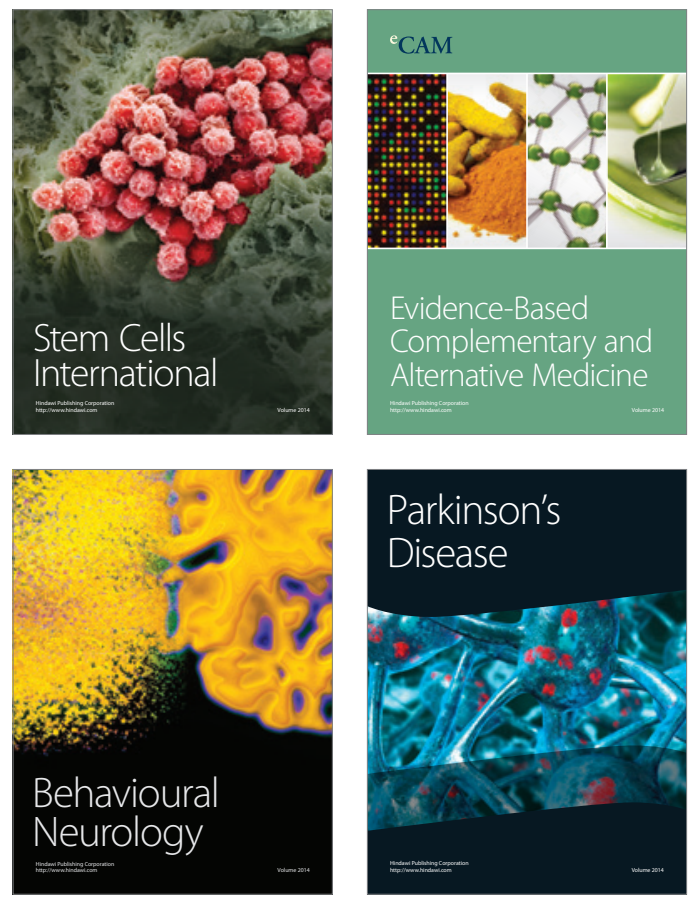
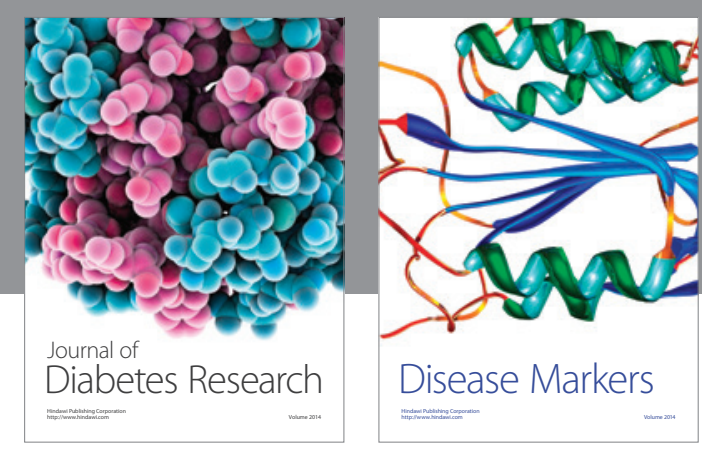

Disease Markers
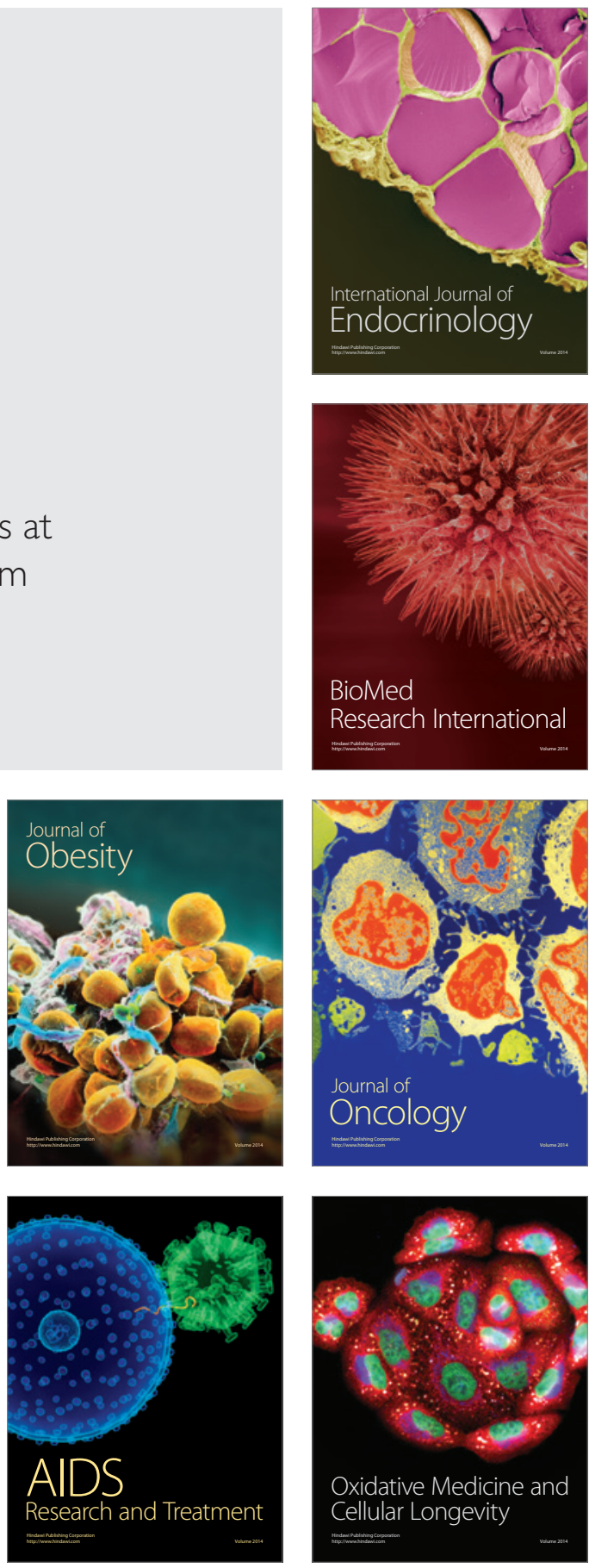